\title{
Lessons learned from avalanche survival patterns
}

\author{
Colin K. Grissom MD
}

See related research article by Haegeli and colleagues at www.cmaj.ca/cgi/doi/10.1503/cmaj.101435

Competing interests:

Colin Grissom was a

consultant for Black

Diamond Equipment Ltd.

(manufacturer of the

AvaLung), and received

outdoor equipment in lieu

of payment.

This article was solicited and has not been peer reviewed.

\section{Correspondence to:} Dr. Colin K. Grissom, colin.grissom@imail.org

CMAJ 2011. DOI:10.1503 /cmaj.110347
$T$ he study by Haegeli and coauthors in $C M A J$ provides new insight into survival patterns after complete avalanche burial. ${ }^{1}$ The authors report survival curves from data for 301 complete avalanche burials in Canada from 1980 to 2005 and compare them with the standard survival curve derived from Swiss data for 946 complete burials during the same period. The Swiss data, which have remained remarkably consistent since first reported in $1994,{ }^{2}$ show survival of more than $90 \%$ of people in the first 15 to 20 minutes of burial, followed by a steep decline in survival to $35 \%$ from 20 to 35 minutes of burial because of asphyxiation in most situations. The curve then plateaus until 90 minutes owing to survival of those with an air pocket, but then drops off because of hypothermia complicated by hypercapnia and hypoxia.

Haegeli and coauthors report that the overall proportion of people who survived was $47 \%$, with no significant differences between the Canadian and Swiss data sets. However, the probability of survival by duration of burial did differ significantly between the two samples. The proportion of survivors was significantly lower in Canada than in Switzerland among people buried for 11-20 minutes and among those buried for more than 35 minutes. Compared with the Swiss survival curve, the Canadian survival curve showed an earlier and quicker drop in survival in the early stages of burial $(<35$ minutes) and poorer survival associated with

\section{KEY POINTS}

- Data from Switzerland have traditionally been used to depict the course of survival after complete avalanche burial.

- In a study comparing Canadian and Swiss data, the Canadian survival curve showed a quicker drop in survival in the first 35 minutes of burial and poorer survival associated with prolonged burial.

- Poorer survival probabilities in Canada were offset by shorter extrication times, which resulted in similar overall proportions of survivors in the two countries.

- Asphyxia was the most common cause of death during complete avalanche burial, especially in wetter, denser snow.

- Education on avalanche safety should become a public health imperative in avalanche-prone regions.

prolonged burial. That the overall proportion of survivors did not differ between the two countries is a consequence of the shorter extrication times in Canada (median 18 minutes v. 35 minutes in Switzerland).

The Swiss survival curve is based on robust data and has been thought to apply throughout the world. The Canadian data, however, show that different geographic regions may have different survival curves. This has implications for avalanche rescue. In Canada, quick extrication, preferably within 10 minutes after burial, is important to survival. This means that companions of a buried individual need to be prepared with avalanche transceivers, probes and shovels to find and dig out the person quickly. Organized rescue takes longer, with less chance of survival. This may explain the poorer survival after 35 minutes in the Canadian data set: more remote locations, where it takes an organized rescue team longer to reach an avalanche accident site, decrease chances of survival. The emphasis on companion rescue is clear from the Canadian data. However, with less than $50 \%$ of people surviving a complete avalanche burial, even when transceivers are used, ${ }^{4}$ prevention is the key.

Haegeli and coauthors analyzed the Canadian data extensively, focusing on whether specific outdoor activities, snow climate and trauma influenced survival. Although the proportion of snowmobilers who died was greater than that among skiers in Canada, the comparison of survival curves between snowmobilers and skiers was not different. This is informative because there were no snowmobilers in the Swiss data set. Use of snowmobiles for backcountry travel has increased in North America; however, such use did not significantly affect the survival curve in the Canadian sample and did not explain the difference between the Canadian and Swiss overall survival curves.

A novel insight from the Canadian data set is the difference in survival curves by snow climate. The drop in survival occurred earliest in the maritime snow climate. This climate is found at lower elevations and has wetter and denser snow that is known to accelerate asphyxiation. ${ }^{5}$ The continen-

All editorial matter in CMAJ represents the opinions of the authors and not necessarily those of the Canadian Medical Association. 
tal snow climate - which occurs in colder, higher elevations and has the least dense snow - was associated with the latest drop in survival. The transitional snow climate has intermediate snow characteristics but has an early drop in the survival curve similar to the maritime snow climate. This may be due to early trauma deaths in addition to deaths from acute asphyxiation. The effect of snow climate in the Canada data set shows the major influence of asphyxiation on survival in the early stages of burial.

A limitation of the study by Haegeli and coauthors is that the Swiss data set did not include cause of death. Although the incidence of trauma-related deaths among avalanche victims appears to be lower in Europe and the United States ${ }^{6}$ than in Canada, caution needs to be exercised when comparing the Swiss survival curve with the Canadian survival curves presented by Haegeli and coauthors with and without trauma-related deaths included.

Asphyxia was the most common cause of death during complete avalanche burial in Canada. In a recent study, it caused $75 \%$ of 204 avalanche-related deaths. ${ }^{7}$ Even in the transitional snow climate, which had the highest proportion of deaths due to trauma, asphyxia still accounted for more than two-thirds of the deaths. The chances of survival are not good for a completely buried avalanche victim, even when companions trained in avalanche rescue are on hand. Therefore, in addition to prevention, methods to improve survival need to focus on preventing death from asphyxiation. Such methods include inflatable air bag systems worn in a pack that help to prevent complete burial ${ }^{8}$ and an emergency breathing device that delays the onset of asphyxiation after complete burial by diverting expired air away from inspired air. ${ }^{5}$

The observations made by Haegeli and coauthors show us that avalanche survival data from Switzerland may not be applicable to Canada or other avalanche-prone regions. The Canadian data confirms that avoidance of avalanches is the best way to survive, and education on avalanche safety should become a public health imperative in avalanche-prone regions.

\section{References}

1. Haegeli P, Falk M, Brugger H et al. Comparison of avalanche survival patterns in Canada and Switzerland. CMAJ 2011;183:78995.

2. Falk M, Brugger H, Adler-Kastner L. Avalanche survival chances. Nature 1994;368:21.

3. Grissom CK, Radwin MI, Scholand MB, et al. Hypercapnia increases core temperature cooling rate during snow burial. J Appl Physiol 2004;96:1365-70.

4. Hohlrieder M, Mair P, Wuertl W, et al. The impact of avalanche transceivers on mortality from avalanche accidents. High Alt Med Biol 2005;6:72-7.

5. Grissom CK, Radwin MI, Harmston $\mathrm{CH}$, et al. Respiration during snow burial using an artificial air pocket. JAMA 2000;283: 2266-71.

6. McIntosh SE, Grissom CK, Olivares CR, et al. Cause of death in avalanche fatalities. Wilderness Environ Med 2007;18:293-7.

7. Boyd J, Haegeli P, Abu-Laban RB, et al. Patterns of death among avalanche fatalities: a 21-year review. CMAJ 2009;180:507-12.

8. Brugger H, Etter HJ, Zweifel B, et al. The impact of avalanche rescue devices on survival. Resuscitation 2007;75:476-83.

Affiliations: Colin Grissom is with the Department of Critical Care Medicine, Intermountain Medical Center, Murray, Utah, and the University of Utah, Salt Lake City, Utah.

Acknowledgement: The author acknowledges Dr. Martin Radwin for his critical review of the manuscript. 